\title{
Counselling for Rehabilitation of Internal Displaced Individual: Post Crisis Interaction and Recovery
}

\author{
Stephen O. Oboh ${ }^{1 *} \quad$ Omonyemen J. Oboh ${ }^{2}$ \\ Department of Education, Faculty of Arts and Education, Benson Idahosa University Nigeria \\ Department of Pharmaceutical Microbiology, College of Pharmacy, Igbinedion University Nigeria
}

\begin{abstract}
This research focuses on counselling for Rehabilitation of internal displaced individuals, Post crisis interaction and recovery (IDPs) in Nigeria. The thriving concept of this study is the counselling that bring about wholesome rehabilitation with positive self-concept among internal displaced individuals in IDPs. The paper identifies the grave challenges faced by the displaced persons, points out the importance of counselling as part of measures to assist IDPs and the role of key stakeholders such as civil society organisations (CSO) and Educational Intuitions; governmental and non-governmental organizations. Thus, the challenges facing IDPs needs a collaborative effort in ameliorating their plight. Therefore, this paper discusses the Concept of Internally Displaced Persons (IDPs), Challenges facing the Internally Displaced Persons (IDPs) in Nigeria, The Role of Stakeholders in Tackling the Challenges of IDPs in Nigeria and Implication of the challenges for Counselling.
\end{abstract}

Keywords: Internally Displaced Persons, Stakeholders, Counselling and Roles

DOI: $10.7176 / \mathrm{JEP} / 11-15-10$

Publication date:May $31^{\text {st }} 2020$

\section{Introduction}

The problem of displaced persons has in recent years become a global concern with its implications (Ladan, 2001). It is on record that the total number of displaced persons is currently estimated around fifty million worldwide, with the majority of these people in Africa and Asia (Olobo \& Obaji, 2016). Displacement across the country in Nigeria is as a result of communal violence, internal armed conflicts and natural disasters.

In any conflict situation and particularly those with ethnic or religious underpinnings, the humanitarian needs are immense and the means to satisfy those needs within the conflict area are severely limited. Internally displaced civilian populations move from one place to another seeking safety and protection inside their own country. Forced population movements resulting in mass exoduses constitute by their very nature infringements on international human rights and humanitarian law. In Nigeria, conflicts arising from the activities of Boko Haram in the North East and Fulani herdsmen have resulted in high threats to lives and properties, death of thousands displacements of millions of people.

Contrary to the expectation of the world population, the new world order has been characterized by more unstable and turbulent conflict situations, unhealthy power politics, destructive ethnic insurgencies, national rivalries, religious bigotry, government hypocrisy and endemic poverty, manufactured by globalization.

This study therefore seeks to critically examine the counselling of internal displaced persons in IDPs and post crisis interaction and early recovery of IDPs in Nigeria, with a view of establishing the challenges and explanatory factors and the way forward for an effective management of IDPs, for peace, conflict resolution and sustainable development in Nigeria. This study is aimed at counselling of IDPs, the factors and issues of resettlement, rehabilitation and reintegration, the way forward and conclusion.

\section{The Concept of Internally Displaced Persons (IDPs)}

At present, there is no internationally agreed definition of who is an internally displaced person but the United Nations (UN) working definition of IDPs is.

Displaced persons under international law are persons or groups of persons who have been forced or obligated to flee or to have cause to leave their homes or place of habitual residence in particular, as a result of or in order to avoid the effect of armed conflict, situations of generalized violence, violations of human rights or natural or human-made disasters, and they must have either remain within their own national borders (as internally displaced persons) or they must have crossed an internationally recognized state border (as refugees), (Ladan, 2006). Hence displaced persons are of two categories: Refugees and Internally Displaced Persons (IDPs).

According to Olawale (2016), Internally Displaced Persons in Nigeria suffer disproportionately from different problems such as malnutrition, sickness, insecurity in the camps, lack of access to education, idles among others. The vulnerability of displaced persons is a major reason why sustainable strategies for rehabilitation must be considered and implemented at the shortest delay possible. There are a lot of challenges inhibiting effective rehabilitation of IDPs in Nigeria.

One of the challenges inhibiting the rehabilitation of internally displaced persons is insufficient understanding of the rights of IDPs as set out in the UN Guiding Principles on Internal Displacement and the Kampala Convention. 
These rights include the right to life, freedom of movement, association, dignity of human person, personal liberty, right to private and family life, etc. IDPs usually suffer the worst violation of their fundamental human right (Alobo and Obaji, 2016).

Security threat is one of the challenges inhibiting the rehabilitation of IDPs in Nigeria, according to Olawale (2016) in September 2015, the deadly terrorist group, Boko Haram, in a suicide mission, attacked members of IDPs Camps in Madagali and Yola, killing 12 persons. In one of the attacks, bombs were reported to have been detonated inside a tent at the IDP camp. These among others are security threats faced by members of IDP camps in Nigeria. Yet to recover from psychological trauma from the loss of families, friends and properties, displaced persons are faced with security challenges coupled with a responsibility to protect themselves in their various camps. The inadequacy of security at the IDP camps opens them to attacks from terrorists and armed robbers. Similarly, Kayode (2015) opined that most camps are unguarded. The camp in Dalori is close to Konduga, a dangerous territory close to Sambisa Forest.

Alobo and Obaji (2016) stated that shelter for IDPs in Nigeria is insufficient and most times do not stand the test of time and weather. Many existing shelters have been damaged or destroyed. Report shows that IDPs live in churches, mosques, town halls, abandoned and uncompleted buildings and where available, other forms of make shift camps which are grossly inadequate and unsuitable for accommodating the surge in displaced populations. These shelters are not as a result of government effort but as a result of the individual's effort to survive. The shelters are often overcrowded and unsuitable in terms of water and sanitation facilities, cooking and privacy, especially for women. There is often no proper waste management and electricity. This explains the regularity of hygiene based epidemics in camps. Furthermore, Olawale (2016) opined that in February 2016, IDPs in Gwoza were evacuated, and many of the IDPs protested since they have no home to lay their heads. Similarly, Kayode (2015) opined that the camps are overcrowded, run down and are struggling to accommodate the increasing number of displaced people. The living conditions are atrocious, unhealthy, and dangerous. Some IDPs are moving back to their villages out of frustration. And the villages are actually the most dangerous of places to be in at the moment.

The challenge of malnutrition in IDP camps cannot be over emphasized, according to Olawale (2016) in February 2016, news reported that 450 internally displaced persons died of malnutrition. Kayode (2015) opined that malnutrition in both adults and children is occurring at alarming rates in the camps. The worst affected are children. Arriving with other health conditions, mental and physical, children are exhibiting worrying signs malnutrition. These signs and symptoms were recorded in an April 2015 UNICEF report, "Missing Childhoods". The report states the children in the camps showed back then an 18 level threshold of malnutrition, above the globally recognized emergency threshold of 15 . The situation is dire. Further health problems exacerbated by the ill-equipped and unhygienic camps are malaria, typhoid, cholera and high blood pressure. Polio and measles are still endemic and a major public health concern for children. More ailments are undiagnosed as there are no health checks carried out in some camps.

Alobo and Obaji (2016) things are made worse by the fact that access to health care in Nigeria generally and the North East in particular is severely constrained for both the IDPs and host communities as a result of the destruction of health care facilities and health care workers. Outbreak of disease has increased in areas affected by dislocation. There is also the case of lack of access to vaccinations. The number of cholera cases among IDPs is seriously on the increase. More ailments are undiagnosed as there is no health checks carried out in these camps.

Corruption is one of the major challenges to the rehabilitation of IDPs in Nigeria; according to Kayode (2015) funds meant for caring for IDPs are redirected, embezzled and used for personal gratification. With women coming in pregnant after enduring months of rape from the terrorist groups, a huge number of malnourished children and traumatized adults. Men lucky to have survived have nothing. One is aware that this has triggered responses from the federal and state governments, and international organizations that are rendering one form of humanitarian support/assistance or the other. Officials were recruited to cater to the problems of the displaced. However, these funds made available and the humanitarian services are embezzled by the same people saddled with the responsibility to ensure the care of IDPs. On the other side of the problem, according to Alobo and Obaji (2016) presently, Nigeria has no legislation that deals explicitly with IDPs and there is no specific institution equipped to handle matters relating to IDPs. This has made caring for IDPs very porous, inconsistent and left to chance.

\section{Challenges facing the Internally Displaced Persons (IDPs) in Nigeria}

The challenges of internally displaced persons either overtly or covertly has a tremendous negative effect on Nigerians and inimical to development. The following are some of the challenges faced by

IDPs in Nigeria (Azam, 2009)

a. Insecurity: Women and girls are being raped on daily basis as a result of insecurity in the camps. Youths indulge in hard drugs, smoking and other criminal activities.

b. Trauma and Bitterness: The IDPs are traumatized and frustrated because of the situation they find themselves. Most of these IDPs live in bitterness due to painful separation from their spouses, families and loved ones. 
c. Hunger and Starvation: It is said that a hungry man is an angry man and because of the level of hunger and starvation faced by the IDPs you see them protesting and demonstrating with their children at the camps.

d. Acute Malnutrition: When one is not feeding well, it has an effect on one's health such as changing the colour of one's hair, eyes and teeth which may result to death. It is discovered that people give them only one type of food item i.e. carbohydrate which affects them not to have a balanced diet.

e. Sexually Transmitted Diseases: This is also another challenge that the IDPs are facing, they have unprotected sex which result to all kinds of STDs like HIV/Aids, gonorrhoea, syphilis etc. They also suffer from hypertension, diabetes and other diseases due to lack of medical health facilities.

f. Education: The IDPs are facing the challenge of educating their children or family members because they are always in transit or floating. More to that there are no provisions by government in this regard.

g. Rights of IDPs: There is insufficient understanding of the rights of IDPs as set out in the UN guiding principles on Internal Displacement and the Kampala Convention. These rights include the right to life, freedom of movement, association, dignity of human person, personal liberty, right to private and family life etc.

h. Shelter/Accommodation: The most common shelter used by IDPs in Nigeria are schools, tents, bunkhouses, churches, mosques, town halls, abandoned and uncompleted buildings. How can human beings live in these places comfortably?

i. Waste Management and Electricity: There is often no proper waste management and electricity for the IDPs. This explains the regularity of hygiene based epidemic in camps and total darkness in camps.

j. Lack of Good Water: Because of the overcrowded nature of camps, it becomes difficult for the IDPs to access good water for cooking and sanitation facilities.

\section{Implications of the challenges for Counselling}

Addressing the challenges of IDPs is primary the responsibility of government, however, it has implication for counselling. Counselling generally is a helping process to address individuals, groups and societal problemsemotionally, mentally, psychologically, socially and economically. In fact, apart from food, shelter, clothing and physical wellbeing, a very important need of IDPs is counselling service. The sudden experiences of homelessness, loss of loved ones, properties, living in insecure states etc creates series of psychological problems such as posttraumatic stress disorder (PTSD), insomnia, depression, hallucinations, eating disorders among others and attendant effects that if counselling is not provided some of them may become psychotic or attempt suicide. Therefore, the challenges of IDPs pose a lot of implications for counselling (Bookings Institutions, 2005):

a. Considering the challenges confronting displaced persons and vulnerability of women and children, there is a need for counselling to accelerate effort in collaborating with other stakeholders in recovering and rehabilitating these displaced persons at the shortest possible time.

b. By way of socio-economic integration, the present situation of IDPs especially women and children need assessment to determine their need. The IDPs need to be equipped and prepared by means of vocational counselling for skill acquisition and training. This is to prepare them to survive physically, mentally, socially and economically while in camp and when they leave the camps (Kasali, 2016).

c. It behoves on counselling to educate IDPs in camps on their sexual behaviours including the dangers of unprotected sex to avoid sexually transmitted diseases.

d. Through the use of appropriate therapies in counselling those that are traumatized will regain themselves and will be healed emotionally to move on with their lives.

e. In the area of counselling for tolerance in diversity the IDPs will be helped to respect one another, in all their diversity of belief, culture and language. Differences within and between societies should be neither feared nor repressed, but cherished as a precious asset of humanity. A culture of peace and dialogue among all people should be actively promoted.

f. The challenges of IDPs call for counselling in the area of independence, fear of violence, oppression or injustice and promote equality of rights, opportunities and solidarity.

\section{The Role of Stakeholders in Tackling the Challenges of IDPs in Nigeria}

The key stakeholders here are the individuals, civil society organisations, educational institutions, government and international organisations (NGO); The stakeholders have roles to play in the challenges facing the IDPs by responding to the situation (Alobo \& Abaji, 2016). These roles area as follows:

\subsection{The Role of Individuals:}

The Individuals have roles to play. These include:

1. The role to love the IDPs and care for them because they are human beings and fellow citizens, we need 
to embrace them, go close to them, pray, cry and play with them. Make them feel loved and give them the sense of belonging.

2. Individuals can provide the IDPs with gift items like clothes, shoes, food items, toys for the children, cream, perfumes and so on. We have to sacrifice our money and buy them good gifts.

3. The individuals can extend their hands of care through provision of food, clothing, shelter that will heal the emotional effects of what they have been through. We need to restore their dignity, and through love and care

4. Individuals may also provide shelter/accommodation to the IDPs.

\subsection{Role of Civil Society Organisations (CSOs)}

In addition to the individual roles, the CSO can assist the IDPs

The scope of activities for civil society groups for displaced persons may include the following;

1. Civil society organizations (CSOs) can play the role of monitoring situations of forcible displacement in the state, in order to ensure that it does not amount to arbitrary displacement by states.

2. The civil organizations can assist the victims to obtain a legal remedy, including compensation.

3. CSOs can advocate for legal or policy frameworks to address gaps related to durable solutions.

4. They can assist displaced persons with skills and the creation of livelihood opportunities, to enable them to start rebuilding their lives.

5. They can also contribute to peace-building activities aimed at ensuring good relations between the displaced persons and the local communities where they intend to settle permanently (Falabi, 2014).

\subsection{Role of Educational Institutions}

1. Educational institutions have a role of providing quality education as a key factor in countering the risk of radicalisation among youths. This is premised on the grounds that youths who have received even a little education are more inclined to view unreasonable violence negatively and are less susceptible to ideological brainwashing by extremist groups (Martin-Rayo, 2013)

2. Efforts to provide adequate protection and assistance to internally displaced persons must be based on accurate information about their number (reflecting the number of children, women and men in different age groups) in all locations such as camps, cities, rural settings. Educational institutions could embark on research to provide data on numbers and state of affairs of IDPs in the country to give adequate guidance for intervention.

\subsection{The Role of Government}

Addressing the problems of IDPs is primarily the responsibility of the government. This requires the taking of concrete steps to prevent arbitrary displacement, protect and assist the IDPs and find durable solution to their problems. The role of government according to Bookings (2005) includes:

1. Government has the responsibility to prevent overt conditions on their territory that might compel population to flee.

2. Raising national awareness for recognized problems and addressing same.

3. Adequate medical care should be given to IDPs especially to their pregnant, nursing mothers and children. Their children should be immunized to avoid being affected by vulnerable diseases.

4. The IDPs also need to be empowered; government should provide them with vocational training and skill acquisition so that they don't stay idle while in camp.

5. Government should provide IDPs with adequate security; make sure that their lives are being secured before sending them back to their homes. Also the camp they live should be guarded by the security armed forces to make sure that further attacks both internally and externally are prevented.

6. The IDPs should not only be provided with carbohydrate food. Well balanced diet should be given to them so that they will not be malnourished.

7. While the IDPs are still in camp, they need to be educated on pre-marital sex and the dangers of unprotected sex to avoid sexually transmitted diseases.

8. Good shelters should be provided for them to avoid effects of cold. Also good source of water should be made available for them to prevent water born diseases.

9. The government should provide a national legal framework to develop laws to uphold the rights of IDPs.

10. The role of government is also to collect data so as to obtain credible information needed on the numbers, location and conditions of IDPs in order to design effective policies and programmes.

11. Government should provide for the education of the children while the period of displacement lasts and even after for children who become orphans with no one to care for them. 
12. To provide training programmes for government officials including camp administrators, military and police exposing them to the rights and needs of the displaced and their own official duties to protect and assist them.

13. Participation of IDPs in Decision Making: Engaging displaced persons in consultation and building upon their skills. The participation of women can reduce their vulnerability to sexual harassment and violence.

14. Government owe it as a duty to establish conditions to allow IDPs to return voluntarily, in safety and dignity, to their places of habitual residence.

15. Allocation of adequate resources to the extent they can, to address situations of internal displacement.

16. Cooperation with international, regional and local organizations in providing assistance to IDPs.

\subsection{The Role of Non-Governmental International Organisations (NGOs):}

The international actors here are the international free donors and humanitarian agencies that help in preventing displacement and providing protection and assistance to those displaced. Their roles in helping IDPs are thus:

1. In line with the United Nation's guiding principles on Internal Displacement of 1998 and the African Union Convention for the Protection and Assistance of IDPs in Africa, they should help in preventing displacement and providing protection and assistance to those displaced.

2. They should actively play role of providing funding from the Commonwealth of Nations and gifts to countries that are in dear need of such assistance.

3. International actors have the role to engage indigenous researchers and NGOs dedicated to advancement of women and children to collate and analyse data to generate comprehensive result for proper intervention.

4. As part of their role, they should provide a comprehensive humanitarian support and training programme to equip IDPs with skills for better livelihoods.

5. The provision of health facilities and services to the IDPs. The World Health Organization (WHO) has the role to intervene in cases like this so as to remedy and help the situation.

\section{Conclusion}

In conclusion, the challenges of Internal Displacement remain a pressing issue in Nigeria. while some significant displacement crises have subsided due to the cessation of hostilities and tens of thousands of IDPs have been able to return to their original place of residence, over a million more in the country remain in a precarious situations and new situations of internal displacement continues to occur. A great deal therefore remains to be done to address IDPs Protection and Assistance needs, to find durable solutions to their plight and to prevent further displacement from taking place.

Based on the reviews made, it is observed that embracing and assisting the IDPs by giving them shelter and basic needs such as food, cloth, water and so on will help them. Apart from these basic needs supplies, the IDPs need to be counselled, and equipped with skills to overcome the emotional trauma that is usually associated with such dehumanising experiences. This requires intervention of different agencies, government and nongovernmental bodies.

However, the value of good governance, social welfare and functional institutions engendering nation building and true dividends of democratic governance for the people should be ensured. . Also, the government should address the root courses and challenges of displaced persons and Internal conflicts by taking appropriate measures with respect to the resolution of conflicts, the promotion of Peace and reconciliation and respect for human rights.

\section{RECOMMENDATIONS}

There is no doubt that to prevent internal displacement, protect the displaced during dislodgment, and find long lasting solutions for them once the cause of dislocation no longer exists requires respect for human rights and in armed conflict situations, the protective rules of international humanitarian law. As a result, the following recommendations are made:

1. The greatest good that will be done to displaced persons in Nigeria is not only to protect, eliminate them but to introduce counselling to all IDPs who will counsel them in all areas of living like appointment, marriage, family and social areas.

2. The fundamental human rights of all citizens should be maintained at all times. Agreed that the environment may be engulfed in violence, it is no ground to violate the rights of people. Adequate steps must be taken to alleviate the plight of IDPs.

3. Government should ensure that where relief materials are sent to IDPs those materials should not be diverted for other use. 
4. Adequate security mechanism should be put in place at the camp sites to relax the apprehensive minds of the IDPs while there.

5. It is imperative to speedily recover and rehabilitate men, women and children in these camps to facilitate proper integration of IDPs back into the various social structures, thereby eliminating tendencies of social vices.

6. The House Committee on IDPs and the National Assembly as a whole should embark on legislative processes that will lead to the domestication of African Union Convention for the Protection and Assistance of Internally Displaced Persons in Africa. This treaty reinforces the state's Primary responsibility to protect the rights and well-being of people forced out of their homes due to conflict, violence, disaster and human rights abuse.

\section{REFERENCES}

Alobo, E.\&Obaji, S. (2016). Internal displacement in Nigeria and the case for human rights protection of displaced persons. Journal of Law, Policy and Globalization, 15, 26-33.

Azam, J.P. (2009). Betting on Displacement: Oil, violence, and the Switch to Civilian Rule in Nigeria. Bookings Institution (2005). University of Bern Project on International Displacement: Addressing Internal Displacement: A Framework for National Responsibility.

Falobi, F. (2014). Nigeria: Coping with challenges of internally displaced persons. Allafrica. Available from: www.m.allafrica.com [Accessed 15 August, 2014.]

Godwin, O. I, (2016). The Politics of Resettlement, Rehabilitation and Reintegration of internally displaced persons (IDPs) in Northern Eastern Region of Nigeria, 1, 2, 22 - 26

Grace, W. A., (2017). Challenges of Internally Displaced Persons (IDPs) in Nigeria: Implications forcounselling and the role of key stakeholders, 5, 2, 21-27.

Kayode, O (2015). Exploitation of internally displaced persons in Nigeria.Retrieved from http:// www.opinionnigeria.com/exploitation-of-internally-displaced-persons-in-nigeria-bykayode-ogun damisi/\#sthash.PIW66IyV.dpbs.

Olawale, R. (2016). Strategies for rehabilitating IDPs in Nigeria.Retrieved from http:// omojuwa.com/2016/03/olawale-rotimi-strategies-for-rehabilitating-idps-in-nigeria/

Oluwole, I. O., Eme, O. I., (2015). Rehabilitation of IDPs in North East Nigeria: Challenges and Prospects, 73, 2, $20-25$.

U. N, (2004). Guiding Principles on Internally Displacement, $2^{\text {nd }}$ (ed) UN, New York, USA.

Ladam, M.T (2001). Introduction to International Human Rights and Humanitarian Laws, A.B.U Press, Zaria. 